\title{
De-sakralisasi dalam Pembelajaran Bahasa Arab di Indonesia: Analisis Bahasa sebagai Identitas Agama
}

\author{
Desacralization of Learning Arabic in Indonesia: Language as Religious Identity
}

\author{
Yuangga Kurnia Yahya ${ }^{1}$, Umi Mahmudah ${ }^{2}$, Luthfi Muhyiddin ${ }^{3}$ \\ ${ }^{1}$ Universitas Darussalam Gontor \\ 1yuangga4@unida.gontor.ac.id \\ ${ }^{2}$ Qatar University \\ ²umimahmudah@unida.gontor.ac.id \\ ${ }^{3}$ Universitas Darussalam Gontor \\ ${ }^{3}$ luthfimuhyiddin@ unida.gontor.ac.id
}

\begin{abstract}
Learning Arabic in Indonesia is still relatively minimal when compared with other foreign language lessons. One reason is that religious orientation in learning makes it an exclusive and limited subject. This study aims to describe the religious orientation in learning Arabic and its influence on the interest in learning Arabic in Indonesia. This research is a qualitative research by collecting data from several sites that discuss the urgency of learning Arabic for the people of Indonesia. The top five sites with these keywords are Rumaysho.com, BelajarIslam.com, Islampos.com, Kompasiana.com, and kiblat.net. The reasons in studying Arabic from five sites will be classified according to learning orientation that includes religious, academic, professional, and economic orientation. The most dominant orientation will be analyzed with the approach of language and identity of Yasir Suleiman's perspective on two functions of language, as an instrument of communication and as a symbol of identity. This research found that stereotyping of Arabic makes it even more exclusive and closed to non-Muslims in Indonesia. Learning Arabic itself is not only limited to religious orientation, but makes it as the function of language itself, as an instrument of communication.
\end{abstract}

Keywords: Arabic language teaching, religious language, religious identity

\section{INTISARI}

Pembelajaran bahasa Arab di Indonesia masih tergolong minim bila dibandingkan dengan pembelajaran bahasa asing lainnya. Salah satu alasannya adalah orientasi religius dalam pembelajarannya membuatnya menjadi pelajaran yang eksklusif dan terbatas. Penelitian ini bertujuan memaparkan orientasi religius dalam belajar bahasa Arab dan pengaruhnya pada minat pembelajaran bahasa Arab di Indonesia. Penelitian ini merupakan penelitian kualitatif dengan mengumpulkan data dari beberapa situs yang membahas urgensi pembelajaran bahasa Arab bagi masyarakat Indonesia. Lima situs teratas dengan keywords tersebut adalah Rumaysho.com, BelajarIslam.com, Islampos.com, Kompasiana.com, dan kiblat.net. Dari kelima situs tersebut akan diklasifikasikan sesuai orientasi pembelajaran yang mencakup orientasi religius, akademik, profesional, dan ekonomis. Orientasi yang paling dominan akan dianalisis dengan pendekatan bahasa dan identitas agama perspektif Yasir Suleiman tentang dua fungsi bahasa, yaitu sebagai instrumen komunikasi dan sebagai simbol identitas. Penelitian ini menemukan bahwa stereotyping terhadap bahasa Arab tersebut membuatnya semakin ekslusif dan tertutup bagi non-Muslim di Indonesia. Belajar bahasa Arab sendiri tidak hanya terbatas pada orientasi religius saja, tapi menjadikannya sebagaimana fungsi bahasa itu sendiri, yaitu sebagai instrumen komunikasi.

Kata kunci: bahasa agama, identitas agama, pengajaran bahasa Arab

Panduan sitasi:

Yahya, Y.K., Mahmudah, U., Muhyiddin, L. (2020). De-sakralisasi dalam Pembelajaran Bahasa Arab di Indonesia: Analisis Bahasa sebagai Identitas Agama. JLA (Jurnal Lingua Applicata), 3(2), 57-70 


\section{PENDAHULUAN}

Pembelajaran bahasa asing di Indonesia mengalami peningkatan dari tahun ke tahun. Hal tersebut dapat terlihat dalam data penggunaan bahasa sehari-hari yang dirilis oleh BPS di mana sebanyak 0,35\% penduduk Indonesia menggunakan bahasa asing (Badan Pusat Statistik, 2010). Bahasa asing yang dipelajari juga beragam. Menurut data dari English First (EF) dalam situs anakUI.com, ada lima bahasa asing yang banyak dipelajari masyarakat Indonesia. Kelima bahasa asing tersebut adalah bahasa Inggris, bahasa Korea, bahasa Jepang, bahasa Mandarin, dan bahasa Arab. Bahkan, beberapa institusi pembelajaran juga menambahkan bahasa Perancis sebagai salah satu bahasa asing yang banyak diminati masyarakat Indonesia.

Alasan masyarakat Indonesia untuk mempelajari bahasa-bahasa asing tersebut juga beragam. Bahasa Inggris jelas menempati urutan teratas dikarenakan bahasa tersebut merupakan bahasa pengantar internasional dalam berbagai ranah, baik akademis, politik, ekonomi, bisnis, dan lain sebagainya, dalam rangka membantu pengembangan bahasa Indonesia dan pemanfaatan ilmu pengetahuan dan teknologi (Agustin, 2011). Bahasa Korea dan bahasa Jepang merupakan bahasa yang menjadi favorit setelah merebaknya 'demam Korea' (Ardia, 2014) dan budaya Jepang dalam bentuk anime, manga, dan sebagainya ke Indonesia (Novianti, 2007). Bahasa Mandarin banyak dipelajari untuk menyikapi persaingan bebas di era globaliasi saat ini (Sutami, 2016).

Adapun bahasa Arab yang identik dengan agama Islam banyak dipelajari di Indonesia dengan berbagai latar belakang. Namun, mayoritas latar belakang belajar bahasa Arab di Indonesia didominasi alasan keagamaan seperti memahami AlQur'an, Hadits, dan berbagai syariat Islam yang bersumber dari buku-buku berbahasa Arab atau dalam bahasa Arab (Wahab, 2007) sebagai orientasi religius.

Hal tersebut berbanding terbalik dengan program Arabic for Non-Native Speaker yang diadakan oleh Qatar University selama dua semester misalnya Qatar University website, 2019). Pada tahun ajaran 2019-2020, program yang diadakan Qatar University ini diikuti oleh mahasiswa dari berbagai negara seperti India, Jepang, Korea, Mongolia, Rusia, Norwegia, Kazakstan, Turki, Indonesia, beberapa negara di Eropa dan Afrika, serta beberapa negara di Asia Tenggara. Seluruh peserta tersebut dibagi ke dalam tiga kelompok, yaitu level atas (advance/mutaqaddim), level menengah (intermediate/mutawassith) dan level pemula (elementary/mubtadi'). Di kelas mutaqaddim, peserta terdiri atas $64 \%$ Muslim dan 36\% non-Muslim. Di kelas mutawassith, peserta Muslim sebanyak $81 \%$ dari total keseluruhan. Sisanya, sebanyak 19\% merupakan non-Muslim. Terakhir, di kelas mubtadi', peserta nonMuslim mencapai $37 \%$ dari total keseluruhan. Secara total, dari ketiga kelas tersebut, peserta yang non-Muslim 
mencapai $27 \%$ dari total keseluruhan peserta. Jumlah ini menunjukkan minat non-Muslim terhadap bahasa dan budaya Arab yang cukup besar ${ }^{1}$.

Dalam program tersebut, peserta yang berasal dari negara non-Arab dan beragama non-Muslim memiliki kemampuan yang tidak jauh berbeda dengan para pelajar Muslim dalam keterampilan berbahasa Arab. Bahkan beberapa dari mereka mendapatkan predikat penutur terbaik dalam percakapan bahasa Arab di antara non-penutur asli. Hal ini menunjukkan bahwa minat belajar bahasa Arab tidak hanya terbatas pada penutur Muslim, melainkan juga para nonMuslim. Di sisi lain, bahasa Arab dianggap sakral dan suci bagi sebagian besar kalangan umat Islam. Fenomena ini dapat terlihat dari munculnya berbagai kasus yang dianggap mendiskreditkan agama Islam karena penggunaan huruf Arab. Kasus-kasus tersebut di antaranya adalah kasus sandal bertuliskan huruf Arab, kasus pakaian Agnez Mo yang bertuliskan huruf Arab (Ihsanudin, 2019), hingga kaos yang diduga sarat dengan Kristenisasi karena bertuliskan "Doa Bapa Kami" menggunakan huruf Arab.

Berbagai fenomena ini semakin menunjukkan bukti bahwa bahasa Arab

\footnotetext{
${ }^{1}$ Hasil wawancara dengan Dr. Abdullah Abdurrahman, Direktur Arabic for Non-Native Speaker Program, Qatar University pada 15 Februari 2020.
}

menurut mayoritas masyarakat Muslim Indonesia adalah bahasa yang suci dan eksklusif. Bahasa Arab yang berfungsi sebagai alat komunikasi dan penyampai pesan dianggap sebagai sesuatu yang sakral dan tidak bisa disalahgunakan. Pembelajaran bahasa Arab di Indonesia yang sangat ditekankan terutama di kalangan para santri di pesantren-pesantren di Indonesia menjadi salah satu pemicu berkembangnya pandangan tersebut. Sebagai contoh, pesantren yang dikenal dalam pembelajaran bahasa Arab di Indonesia adalah Pondok Modern Darussalam Gontor. Sistem pembelajaran proaktif menggunakan metode langsung yang dikembangkan dan disertai pembentukan lingkungan berbahasa yang kondusif menyebabkan penguasaan bahasa Arab menjadi lebih mudah. Bahasa Arab di Gontor bukanlah tujuan utama pembelajaran, tetapi justru menjadi sarana pembelajaran agama Islam sehingga para santri dapat mempelajari Islam langsung dari sumber utamanya. Hal ini yang menyebabkan penggunaan bahasa Arab menjadi sangat sakral (Muhyiddin \& Zharfa, 2018).

Permasalahan tersebut menjadi fokus penelitian ini dengan menganalisis fenomena bahasa dan identitas Muslim di Indonesia menggunakan sampel dari alasan-alasan belajar bahasa Arab di lima website teratas dalam pencarian dengan kata kunci tersebut. Beberapa penelitian telah dilakukan terkait bahasa Arab dan identitas keagamaan di Indonesia. 
Penelitian yang dilakukan Wahyuni (2017) berfokus pada tujuan pembelajaran bahasa Arab dalam konteks simbol agama di Fakultas Tarbiyah dan Ilmu Keguruan IAIN Kendari. Penelitian tersebut menunjukkan tujuan pembelajaran bahasa Arab di FTIK IAIN Kendari adalah mewujudkan kompetensi kebahasaan, mengembangkan kompetensi komunikasi, dan mengintegrasikan pemahaman kebudayaan dalam pembelajaran bahasa Arab. Namun, ketiga tujuan tersebut belum tercapai secara maksimal sehingga perlu rekonstruksi strategi pemahaman mahasiswa terhadap tujuan pembelajaran bahasa Arab.

Penelitian lainnya dilakukan oleh Wahyuni, Ahmad dan Mulyanti (2011). Penelitian ini berfokus pada sikap siswa non-Muslim dalam mengikuti pelajaran bahasa Arab Melayu di SDN 016 Kabupaten Kampar. Tujuan penelitian ini adalah mengetahui sikap siswa nonMuslim dalam mengikuti pelajaran tersebut dan faktor yang mempengaruhinya. Hasil penelitian menunjukkan sebanyak 33,59\% siswa non-Muslim menunjukkan sikap "tidak positif" dalam mengikuti pelajaran bahasa Arab Melayu. Faktor yang banyak mempengaruhi hal tersebut adalah faktor internal dari dalam diri siswa yang tidak menganggap penting pembelajaran bahasa Arab. Salah satu saran dari penelitian tersebut adalah arahan dari guru pengajar untuk memberikan pemahaman bahwa pelajaran bahasa Arab Melayu merupakan pelajaran kebudayaan Arab Melayu dan bukan terbatas pada agama Islam.
Adapun penelitian ini berfokus pada tinggi rendah minat pembelajaran bahasa Arab di Indonesia dengan menganalisis alasan belajar bahasa Arab yang tertera di artikel yang membahas pentingnya belajar bahasa Arab. Penelitian ini adalah penelitian kualitatif dengan menggunakan metode observasi, wawancara, dan dokumentasi. Data yang diperoleh berasal dari lima artikel di website tentang alasan belajar bahasa Arab. Alasan-alasan tersebut akan dianalisis dengan pendekatan bahasa sebagai identitas agama dari Yasir Suleiman.

\section{METODE PENELITIAN}

Suleiman (2003) menjelaskan bahwa bahasa, termasuk bahasa Arab, memiliki dua fungsi, yaitu sebagai instrumen komunikasi dan sebagai simbol dan identitas suatu kelompok. Sifat yang kedua disebut juga sifat primordial bahasa (primordiality of language) yang lahir karena bahasa merupakan produk budaya dan masyarakat (Suleiman, 2003). Dua paradigma yang terjadi adalah nasionalisme, etnisitas, dan identitas yang dikonstruksi melalui bahasa atau sebaliknya, di mana bahasa yang dikonstruksi menjadi simbol identitas, etnisitas, dan nasionalisme tersebut (Rajagopalan, 2016). Namun, dalam banyak kasus, sifat primordial bahasa tersebut seringkali menjadi lebih dominan sehingga menjadi sebuah pemisah antara satu kelompok atau komunitas tutur dengan yang lainnya. Hal tersebut membuat bahasa sebagai alat komunikasi justru berubah 
menjadi pemutus komunikasi dengan pihak lain (Suleiman, 2003).

Bahasa merupakan teknologi yang diciptakan manusia untuk berkomunikasi (Dor, 2015). Menurut Dor, untuk dapat menjadi alat komunikasi, bahasa tersebut harus bersifat intersubyektif dengan adanya kerjasama antara penutur dan mitra tutur (cooperation), pikiran kolektif (collective thought), dan produksi budaya yang sama (cultural production). Bila ia tertutup dan menjadi eksklusif, maka fungsinya sebagai teknologi atau instrumen komunikasi terhambat, bahkan tercederai.

Sakral adalah salah satu aspek dalam agama yang mensucikan suatu benda atau entitas tertentu. Lawan katanya adalah profan 'hal yang biasa`. Suatu benda atau entitas menjadi sakral bukan dikarenakan sifat entitas tersebut, namun lebih kepada kepercayaan yang diberikan para pemeluk agama akan kesucian kepada entitas tersebut. Karenanya, dalam bahasa Inggris, ia disebutkan dengan kata sacred, bukan sacring atau sacral. Hal ini disebabkan konstruksi kesucian merupakan sesuatu yang diberikan (given) (Agus, 2007; Eliade, 1959).

Penelitian sakralisasi dalam pembelajaran bahasa Arab ini menggunakan metode kualitatif. Setelah alasan-alasan pembelajaran bahasa Arab diklasifikasikan, akan dipaparkan orientasi masing-masing alasan pembelajaran. Selanjutnya, akan dianalisis orientasi pembelajaran yang paling dominan. Terakhir, akan dipaparkan hasil analisis stigma pembelajaran bahasa Arab dengan rendahnya minat pembelajaran bahasa Arab di Indonesia.

Sumber data penelitian ini adalah lima situs teratas menggunakan kata kunci 'alasan belajar bahasa Arab'. Kelima situs tersebut adalah rumaysho.com (2016), belajarislam.com (2018), islampos.com (2018), kompasiana.com (2016), dan kiblat.net (2016). Data yang terkumpul diklasifikasikan berdasarkan orientasi pembelajaran bahasa, yaitu orientasi religius, orientasi akademik, orientasi profesional/praktis dan pragmatis, dan orientasi ideologis dan ekonomis (Wahab, 2007:3-4). Data yang telah diklasifikasikan akan dianalisis dengan berfokus pada orientasi religius yang mendominasi alasan yang diberikan dalam pembelajaran bahasa Arab. Orientasi yang paling dominan akan menunjukkan hubungan pembelajaran bahasa Arab di Indonesia dan stigma tentang orientasi pembelajaran bahasa Arab. Data ini akan dianalisis dengan menggunakan dua fungsi bahasa, yaitu bahasa sebagai alat komunikasi dan sebagai simbol atau identitas suatu kelompok (Suleiman, 2003).

\section{HASIL DAN PEMBAHASAN}

Dengan menggunakan kata kunci 'alasan belajar bahasa Arab', peneliti menemukan banyak situs yang memberikan berbagai alasan untuk belajar bahasa Arab. Rumaysho.com misalnya, dikemukakan tujuh alasan untuk belajar bahasa Arab. Artikel berjudul "Tujuh Alasan Harus Belajar Bahasa Arab" yang ditulis oleh Muhammad Abduh Tuasikal, 
M.Sc. pada 12 Januari 2016 menyebutkan beberapa di antaranya, meliputi 1) bahasa Arab merupakan bahasa Al-Qur'an, 2) merupakan syi'ar Islam, 3) bermanfaat untuk memahami syariah dan keilmuan Islam, dan 4) merupakan bahasa yang mulia karena wahyu Tuhan turun dengan bahasa tersebut.

Dalam situs belajarislam.com, terdapat tujuh alasan belajar bahasa Arab. Ketujuh alasan tersebut adalah: 1) bahasa Arab sebagai syi'ar Islam, 2) bahasa Arab sebagai bahasa ritus umat Islam dalam berdoa dan beribadah, 3) kemahiran berbahasa Arab memberikan pengaruh kuat pada cara berpikir (logika), akhlaq, dan agama, 4) dapat serupa dengan sahabat Nabi SAW dan berakhlaq mulia seperti mereka, 5) bahasa Arab merupakan bahasa agama, 6) untuk memahami al-Qur'an dan Sunnah, serta 7) membuat seseorang semakin baik (faqih) dalam ucapan. Artikel ini berjudul "Tujuh Alasan Kenapa Kita Harus Belajar Bahasa Arab" yang mengambil referensi dari buku Iqtidha' Ash-Shirath Al-Mustaqim karya Ibn Taimiyah.

Adapun dalam situs islampos.com, disebutkan pula tujuh alasan bagi seorang Muslim di Indonesia untuk belajar bahasa Arab. Alasan-alasan tersebut adalah: 1) memahami kata-kata dari Allah SWT tanpa mengandalkan terjemahan, 2) memahami hadits Nabi Muhammad SAW, 3) meningkatkan kekhusyuan dalam shalat, 4) memahami kitab-kitab ilmu Islam karangan para ulama, 5) termasuk dalam lima bahasa paling umum di dunia, 6) meningkatkan kesempatan kerja, dan 7) belajar bahasa baru berfungsi meningkatkan kinerja otak dan kekuatan memori. Semua alasan tersebut terangkum dalam artikel berjudul "Inilah Tujuh Alasan Mengapa Anda Harus Belajar Bahasa Arab" yang ditulis oleh Adam.

Situs kompasiana.com dalam salah satu artikel berjudul "Bahasa Arab sebagai Bahasa Internasional" yang ditulis oleh Ardin Jae menyebutkan beberapa alasan untuk belajar bahasa Arab. Pertama, karena bahasa Arab merupakan bahasa Al-Qur'an. Kedua, memudahkan memahami ajaran Islam dari kitab-kitab klasik. Ketiga, susunan katanya tidak terlalu banyak karena umumnya hanya terdiri dari tiga huruf. Keempat, karena bahasa Arab merupakan salah satu bahasa internasional yang penting dalam komunikasi antar budaya dalam ranah ekonomi, politik, dan lain sebagainya.

Terakhir, dalam situs kiblat.net terdapat artikel berjudul "Tujuh Alasan Logis Kenapa Anda Mesti Belajar Bahasa Arab" yaitu ditulis oleh M. Rudy dengan sumber Ilmfeed. Artikel yang ditulis pada 14 juli 2016 ini menyebutkan alasan-alasan yang mengharuskan seorang Muslim di Indonesia belajar bahasa Arab. Alasanalasan tersebut adalah: 1) dengan bahasa Arab dapat memahami ayat-ayat Allah tanpa terjemahan, 2) dapat dengan mudah memahami perkataan Nabi Muhammad SAW, 3) dapat meningkatkan kekhusyuan dalam sholat, 4) untuk memahami ilmu agama dari sumber aslinya, 5) bahasa Arab sebagai salah satu bahasa internasional, 6) 
dapat memperluas peluang kerja, dan 7)

dapat menguatkan memori otak.

Tabel 1. Klasifikasi Orientasi Belajar

\begin{tabular}{lcccc}
\multicolumn{5}{c}{ Bahasa Arab } \\
\multicolumn{1}{c}{ Situs } & $\begin{array}{c}\text { Orientasi } \\
\text { Religius }\end{array}$ & $\begin{array}{c}\text { Orientasi } \\
\text { Akademik }\end{array}$ & $\begin{array}{c}\text { Orientasi } \\
\text { Profesional }\end{array}$ & $\begin{array}{c}\text { Orientasi } \\
\text { Ekonomis }\end{array}$ \\
\hline rumaysho.com & 7 & - & - & - \\
belajarislam.com & 5 & 2 & - & - \\
islampos.com & 4 & 2 & - & 1 \\
kompasiana.com & 2 & 1 & - & 1 \\
kiblat.net & 4 & 2 & - & 1 \\
\hline
\end{tabular}

(Sumber: rumaysho.com, 2016; belajarislam.com, 2018; islampos.com, 2018; kompasiana.com, 2016; kiblat.net, 2016)

Dari berbagai data di atas, orientasi belajar bahasa Arab dapat diklasifikasikan ke dalam empat orientasi (lihat Tabel 1). Data dari situs-situs tersebut yang berkaitan dengan orientasi religius kemudian diklasifikasikan berdasarkan alasan-alasan yang dipaparkan dalam Tabel 2.

Tabel 2. Frekuensi Kemunculan Alasan Belajar Bahasa Arab dengan Orientasi Religius

\begin{tabular}{lc}
\hline Alasan belajar bahasa Arab & Frekuensi \\
\hline Merupakan bahasa Al-Qur'an & 5 \\
$\begin{array}{l}\text { Merupakan syi'ar Islam } \\
\text { Untuk memahami Al-Qur'an } \\
\text { dan Sunnah }\end{array}$ & 2 \\
$\begin{array}{l}\text { Untuk memahami syariat } \\
\text { Islam kekhusyuan }\end{array}$ & 3 \\
$\begin{array}{l}\text { Bahasa ritus umat Islam } \\
\text { Menambah dalam beribadah }\end{array}$ & 3 \\
$\begin{array}{l}\text { Memahami kitab ilmu Islam } \\
\text { Agar serupa dengan Nabi dan }\end{array}$ & 2 \\
Sahabat & 1 \\
\hline
\end{tabular}

(Sumber: data penelitian penulis)

Dari berbagai alasan di atas, hanya ditemukan tujuh alasan berorientasi akademik dan tiga alasan berorientasi ekonomis. Selain itu, tujuan mempelajari bahasa Arab didominasi oleh orientasi religius sehingga menjadikannya sebuah 'tugas suci' yang tidak mungkin dilakukan oleh pemeluk agama lain. Orientasi religius tersebut meliputi sarana untuk memahami Al-Qur'an, hadits, kitab-kitab klasik sebagai sumber rujukan Islam, bahasa ritus dalam beribadah dan berdoa, mengikuti ajaran Nabi dan Sahabatnya hingga meningkatkan kekhusyu'an shalat.

Tujuan pembelajaran yang demikian melahirkan suatu fenomena yang disebut sakralisasi penggunaan bahasa Arab. Pada tahun 2016, Agnez Mo dihujat masyarakat karena menggunakan pakaian yang bertuliskan المتحدة"، 'persatuan/bersatu' (Ihsanudin, 2019: 4849). Ia dianggap melecehkan umat Islam dengan penampilan tersebut. Hal serupa juga terjadi dengan adanya kaos bertuliskan 'Doa Bapa Kami dalam Injil Matius' dalam bahasa Arab yang tersebar di berbagai gerai pakaian. Berita yang beredar berjudul "Kaligrafi yang menyesatkan" (Widjaja, 2008) dan "Lagi- 
lagi Kaligrafi Kristen Beredar, Umat Mesti Hati-Hati” (Hidayat, 2016). Kasus terbaru adalah fenomena sandal yang bertuliskan “" 'kanan' dan “" 'kiri' yang dianggap sebagai sebuah perbuatan yang menghina Al-Qur'an. Mayoritas mereka yang menghujat beralasan bahwa hal tersebut adalah sebuah bentuk penghinaan bagi umat Muslim dan bahasa Arab, bahasa yang digunakan kitab suci mereka dan merupakan bahasa yang sakral.

Sakralisasi seperti ini terjadi bukan tanpa sebab. Orientasi pembelajaran bahasa Arab yang didominasi oleh orientasi religius menyebabkan persepsi masyarakat Muslim terhadap bahasa Arab menjadi sesuatu yang religius juga. Sakralisasi suatu hal dalam agama berarti menjadikan hal yang biasa (profan) tersebut memiliki nilai suci dan sakral (Agus, 2007: 80-81; Eliade, 1959: 12). Kesucian tidak terletak pada suatu benda, melainkan pada persepsi dan konstruksi yang dibangun oleh sistem ritual dan kepercayaan agama tersebut.

Hal ini juga didukung oleh narasi yang menyebutkan bahwa bahasa Arab adalah bahasa yang digunakan manusia pertama, Adam. Bahasa Arab juga merupakan bahasa yang digunakan dalam berkomunikasi dengan Tuhan, malaikat, dan menjadi bahasa yang digunakan di surga kelak (Edwards, 2009:105). Hal ini sejalan dengan alasan pembelajaran yang telah dipaparkan sebelumnya yang menyebutkan bahwa alasan belajar bahasa Arab adalah agar serupa dengan Nabi dan karena bahasa tersebut merupakan bahasa yang suci.
Kitab suci Al-Qur'an adalah sesuatu yang sakral karena ia diyakini sebagai wahyu Tuhan. Bahasa Arab yang menjadi medium Al-Qur'an juga menjadi sacral, khususnya bagi Muslim nonpenutur asli bahasa Arab. Bahkan, tulisan biasa seperti yang tertera pada baju Agnez Mo dan sandal sebagaimana dipaparkan sebelumnya dianggap suci meskipun ia memiliki makna yang profan. Begitu pula dengan kaos bertuliskan ayat Alkitab. Meskipun teks yang tertulis merupakan teks non-Islam, namun persepsi yang terbentuk tetap terperangkap dalam konteks Islam dikarenakan penggunaan bahasa Arab ('Aid, 1989: 96; Suleiman, 2003: 140).

Fenemona di atas membuat gerak bahasa Arab semakin terbatas. Ia dibatasi hanya sebagai bahasa ritual agama Islam dan bersifat suci. Artinya, dominasi pembelajar bahasa Arab di Indonesia adalah Muslim dengan alasan yang religius. Hal tersebut diuraikan pula oleh Dor (2015: 23) dan Suleiman (2003: 32) yang menyatakan bahwa bahasa Arab kehilangan fungsi utamanya sebagai instrumen komunikasi dan sarana penghilang jurang pemisah (bridges the gap). Bahasa Arab lebih identik dengan fungsinya sebagai identitas keagamaan daripada sebagai instrumen komunikasi. Fungsi bahasa Arab sebagai languageprestige lebih dominan daripada languagefunction (Edwards, 1996: 14). Ia memainkan peran sebagai 'pengikat komunitas homogen' (homogeneus community binder) dan sebagai penanda 
identitas keagamaan (Jaspal \& Coyle, 2010: 25).

\section{Bahasa Arab (bukan hanya) bahasa Islam}

Bahasa Arab dan Al-Qur'an memang tidak dapat terpisahkan. Dengan adanya Al-Qur'an, bahasa Arab, khususnya ragam fuscha, tetap terwarisi dan terjaga autentisitasnya hingga saat ini (Fachrudin, 2017: 23). Berbagai ragam dialek bahasa Arab, bahkan di dalam ragam fuscha itu sendiri, menimbulkan kekhawatiran akan hilangnya ragam fuscha. Hal inilah yang mendasari pembukuan Al-Quran dalam satu mushaf. Tak ayal, mempelajari AlQur'an tidak akan sempurna tanpa didahului dengan kemampuan menguasai bahasa Arab. Berbagai ilmu bahasa seperti sintaksis, morfologi, stilistika, dan semantik juga dikembangkan dari AlQur'an (Al-Faruqi \& Al-Faruqi, 2003: 141; Edwards, 2009: 105). Meskipun keduanya tidak terpisahkan, bahasa Arab dan bahasa Al-Qur'an memiliki cukup banyak perbedaan. Salah satunya adalah bahasa Al-Qur'an yang merupakan bahasa tingkat tinggi di dalam sastra Arab. Hal ini disebabkan oleh karena Al-Qur'an diwahyukan kepada Nabi Muhammad SAW pada masa bangsa Arab berada dalam puncak emas kesusasteraan Arab. Hal ini menyebabkan upaya mempelajari bahasa Arab dalam rangka memahami isi kandungan Al-Qur'an berada di tingkat paling tinggi setelah penguasaan sintaksis, morfologi, stilistika bahkan semantik dari bahasa Arab (Al-Faruqi \& Al-Faruqi, 2003: 140-141).
Namun, bahasa Arab tidak hanya sekedar bahasa ritus (liturgical language). Bahasa Arab juga merupakan instrumen komunikasi, bahkan menjadi kendaraan budaya dan peradaban (vehicle for a renowned culture and civilization) (Bakalla, 1984: 87) atau agen budaya (Fachrudin, 2017: 23). Lebih jauh, ia memiliki posisi yang sepadan dengan bahasa Yunani dan Latin dalam transmisi keilmuan di dunia. Berbagai karya ilmu pengetahuan dari Yunani sampai ke Eropa diterjemahkan dan dikembangkan, sehingga membuat ilmu pengetahuan baru berkembang di dunia Arab. Baghdad, Andalusia, dan Sisilia merupakan kota yang menjadi pusat penerjemahan dan pengembangan ilmu pengetahuan (Misbahuddin, 2015: 40). Dengan kata lain, pada zaman keemasan Islam, yaitu abad ke-8 hingga abad ke-11, bahasa Arab menjelma menjadi bahasa ilmu pengetahuan internasional (Bakalla, 1984: 8) atau disebut juga 'bahasa ilmu pengetahuan dan pemikiran' (Khalīfah, 2003: 12)

Selain budaya dan ilmu pengetahuan, pada abad pertengahan, bahasa Arab merupakan bahasa diplomasi dan administrasi internasional. Ia menggantikan posisi bahasa Yunani, Persia, Latin, Mesir Kuno, dan Siriac. Dengan demikian, bahasa Arab menjadi bahasa resmi internasional di Afrika Utara, Mesir, Jordania, Suriah, Iraq, dan Lebanon (Nasution, 1974: 70). Setidaknya 25 negara menjadikan bahasa Arab sebagai bahasa resmi negara mereka dan enam negara 
menjadikannya bahasa resmi kedua. Bahasa Arab juga menjadi bahasa dengan penutur terbanyak di benua Afrika, khususnya negara-negara yang terletak di Afrika Utara (Bakalla, 1984: 16; Bale, 2010: 127; Yahya, 2019: 44-45). Menurut Doochin dalam Babbel Magazine (2019), pada tahun 2019, bahasa Arab dituturkan oleh 313 juta orang di seluruh dunia sehingga menjadikannya bahasa internasional dengan penutur terbanyak ke5 setelah Mandarin, Spanyol, Inggris, dan India.

Data di atas menunjukkan bahwa pengangkatan bahasa Arab sebagai salah satu bahasa resmi PBB bukanlah sebuah kebetulan. Bahasa Arab merupakan bahasa internasional di banyak negara. Mempelajari bahasa Arab merupakan suatu hal yang penting dalam ranah ekonomi, politik, diplomasi, dan pengetahuan di era modern saat ini. Sebuah penelitian menyebutkan bahwa masyarakat Kristen di Asia Barat dan Afrika Utara juga beribadah menggunakan bahasa Arab. Bahkan, Alkitab mereka juga diterjemahkan ke dalam bahasa Arab dan digunakan dalam beribadah (Yahya, 2018). Bale (2010) menyebutkan bahwa mayoritas penutur bahasa Arab di Amerika Serikat adalah berasal dari non-Muslim. Oleh karena itu, bahasa Arab tidak terbatas bagi umat Islam saja. Bahkan di Indonesia pun terdapat empat orientasi pembelajaran bahasa Arab, yaitu religius, akademik, profesional, dan ideologis-ekonomis (Wahab, 2007: 3-4). Berbagai orientasi tersebut sesuai dengan berbagai posisi bahasa Arab di dunia internasional sebagaimana dijelaskan sebelumnya.

Sakralisasi bahasa Arab yang berujung pada eksklusivisme bahasa bagi Muslim di Indonesia membuatnya kehilangan posisinya yang strategis dari berbagai aspek. Pola pikir ini sejalan dengan pola pikir seorang ahli bahasa di Eropa, André Martinet, saat pertama kali meneliti bahasa dari Timur. Menurutnya, bahasa Parsi, Sanskrit, Pali, dan Arab merupakan bahasa suci dan hanya digunakan dalam ritus dan upacara keagamaan serta dikuasai oleh para pemuka agama saja ('Ayāsyi, 1990: 27) atau disebut juga liturgical language (Jaspal \& Coyle, 2010: 18). Padahal sejatinya, hakikat bahasa sebagai intrumen komunikasi dan penyampai pesan tidak dapat dipisahkan dari bahasa apapun, seprimitif apapun bahasa tersebut (Khalifah, 2003: 13). De-sakralisasi bahasa Arab sebagai instrumen komunikasi akan mengembalikan posisinya kembali menjadi bahasa internasional yang tidak terbatas pada agama tertentu.

\section{KESIMPULAN}

Bahasa Arab merupakan salah satu bahasa asing yang diminati di Indonesia dan juga merupakan bahasa internasional. Namun, kesadaran untuk mempelajari bahasa ini masih tergolong rendah dikarenakan sakralisasi penggunaannya. Akibatnya, posisi bahasa Arab di mata masyarakat non-Muslim Indonesia hanya sebagai bahasa agama Islam dan tidak memiliki keuntungan apapun untuk 
mempelajarinya. Alih-alih mempelajari bahasa Arab, mereka lebih memilih mempelajari bahasa Korea, Jepang, Mandarin, dan Perancis. Hal tersebut lahir dari persepsi (bahkan keyakinan) eksklusivisme bahasa Arab oleh umat Islam di Indonesia. Berbagai alasan untuk mempelajari bahasa Arab didominasi alasan religious Islam. Bahkan, semua tulisan berbahasa Arab dianggap suci dan memiliki hubungan erat dengan Al-Qur'an. Hal ini menyebabkan berbagai hujatan masyarakat lahir dari ketidaktahuan mereka bahwa bahasa Arab selain berfungsi sebagai simbol identitas agama, memiliki fungsi yang lebih fundamental, yaitu sebagai instrumen komunikasi dan penyampai pesan.

Penelitian ini memberikan saran untuk mengembalikan bahasa Arab kepada posisinya yang semula atau de-sakralisasi, yaitu sebagai instrumen komunikasi. Sejarah telah membuktikannya sebagai salah satu bahasa yang menjadi transmisi keilmuan, budaya, dan peradaban umat manusia. Fungsi bahasa Arab ini jauh lebih besar dan holistik dibandingkan bila hanya menjadi hak prerogatif umat Muslim. Desakralisasi bahasa Arab bertujuan untuk meningkatkan minat pembelajaran bahasa Arab di Indonesia dan tidak hanya terbatas pada penutur Muslim saja.

\section{DAFTAR PUSTAKA}

'Ayāsyi, M. (1990). Qadhāyā Lisāniyyah wa Chadloriyyah. Dar Tlass.

'Aid, M. (1989). Qadhāyā Mu'āshirah fi ad-Dirāsāt al-Lughawiyyah wa'l
Adabiyyah. 'Alam al-Kutub.

Aceh.tribunnews.com. (2018, 21 Mei).

Heboh Sandal Bertuliskan Huruf Arab, Netizen Marah Dikira Ayat al-Qur'an, Ternyata Ini Artinya. Diakses pada 5 Juli 2020, 8:20 pm WIB dari https://aceh.tribunnews.com/2018/05/2 1/heboh-sandal-bertuliskan-hurufarab-netizen-marah-dikira-ayat-alquran-ternyata-ini-artinya

Adam. (2018). Inilah 7 Alasan Mengapa Anda Harus Belajar Bahasa Arab. Diakses pada 5 Juli 2020, 8:25 pm WIB dari

https://www.islampos.com/inilah-7alasan-mengapa-anda-harus-belajarbahasa-arab-122550/

Agus, B. (2007). Agama Dalam Kehidupan Manusia: Pengantar Antropologi Agama. PT Rajagrafindo Persada.

Agustin, Y. (2011). Kedudukan Bahasa Inggris Sebagai Bahasa Pengantar Dalam Dunia Pendidikan. Deiksis, 03(04), 354-364.

Al-Faruqi, I. R., \& Al-Faruqi, L. L. (2003). Atlas Budaya Islam, Terj.Ilyas Hasan (IV). Penerbit Mizan.

Ardia, V. (2014). Drama korea dan Budaya Popular. Jurnal Komunikasi, 2(3), 1218.

AnakUI.com (2015, 14 Maret). 5 Bahasa Asing yang Banyak Dipelajari Orang Indonesia. Diakses pada 5 Juli 2020, 8:08 pm WIB dari https://www.anakui.com/5-bahasaasing-yang-banyak-dipelajari-orangindonesia/\#5_Bahasa_Mandarin_8220 bahasa_untuk_investasi_masa_depan 8 
221

Badan Pusat Statistik. (2010). Kewarganegaraan, Suku bangsa, Agama dan Bahasa Sehari-hari Penduduk Indonesia: Hasil Sensus Penduduk 2010. Badan Pusat Statistik.

Bakalla, M. H. (1984). Arabic Culture: Through its Language and Literature. Keegan Paul International, Ltd.

Bale, J. (2010). Arabic as a heritage language in the United States. International Multilingual Research Journal, 4(2), 125-151. https://doi.org/10.1080/19313152.201 $\underline{0.499041}$

Belajarislam.com. (2018, 7 Juli). 7 Alasan Kenapa Kita Harus Belajar Bahasa Arab. Diakses pada 5 Juli 2020, 8:24 pm WIB dari https://belajarislam.com/2018/07/7alasan-kenapa-kita-harus-belajarbahasa-arab/

Dor, D. (2015). The Instruction of Imagination: Language as a social Communication Technology. https://doi.org/10.1017/CBO9781107 $\underline{415324.004}$

Doochin, D. (2019, 25 Januari). How Many People Speak Arabic, and Where? diakses pada 5 Juli 2020, 8:41 pm WIB dari https://www.babbel.com/en/magazi ne/how-many-people-speak-arabic/

Edwards, J. (1996). Language, Prestige, and Stigma. In Contact Linguistics. de Gruyter.

Edwards, J. (2009). Language and Identity:
An Introduction. Cambirdge University Press.

Eliade, M. (1959). The sacred and the profane: The nature of religion, Trans. Willard R Trask. In Harcourt, Brace \& World, Inc. New York: A Harvest Book.

Fachrudin, A. A. (2017). Pengantar Sejarah dan Madzhab Linguistik Arab. CV. Lisan Arabi.

Hidayat, S. (2016). Lagi-lagi Kaligrafi Kristen Beredar, Ummat Islam Mesti Hati-hati. Retrieved March 17, 2020, from Kaligrafi-Islam.blogspot.com website: $\quad$ https://perma.cc/Z9C6W9KK

Ihsanudin, I. (2019). Polemik "Tulisan Arab" Pada Busana Agnes Monica (Analisis Teori Interaksionisme Simbolik). Palita: Journal of SocialReligion Research, 4(1), 47-60. https://doi.org/10.24256/pal.v4i1.526

Jae, A. (2016, 23 September). Bahasa Arab sebagai Bahasa Internasional. Diakses pada 5 Juli 2020, 8:27 pm WIB dari https://www.kompasiana.com/ardinjae 157e4a0b56d7a61942c62d00e/bahasaarab-sebagai-bahasa-internasional

Jaspal, R., \& Coyle, A. (2010). "Arabic is the language of the Muslims-that's how it was supposed to be": Exploring language and religious identity through reflective accounts from young British-born South Asians. Mental Health, Religion and Culture, 13(1), 17-36. https://doi.org/10.1080/136746709031 
$\underline{27205}$

Khalīfah, 'Abd al-Karīm. (2003). AlLughah al-'Arabiyyah 'ala Madāriji al-Qarni al-Wāchid wa'l 'Isyrīn. Beirut: Dār al-Gharb al-Islamy.

Misbahuddin, M. (2015). SICILIA: Jembatan Transmisi Keilmuan Islam ke Eropa. Khatulistiwa, 5(1), 32-42. https://doi.org/10.24260/khatulistiwa. $\underline{\mathrm{vi}} \mathrm{i} .263$

Muhyiddin, L., \& Zharfa, H. (2018). The Implementation of Jigsaw Strategy to Improve Students' Active Participation in Learning of Tarjamah, Class of Grade 4 KMI at Third Campus of Darussalam Gontor Islamic Boarding School Academic Year: 1438-1439 H. LISANUDHAD, $5(1)$, 107-130.

http://dx.doi.org/10.21111/lisanudhad. v5i1.2386

Nahimunkar.com. (2016, 17 Juni).

Penampakan Kaos Bertuliskan Doa

Kristiani Beredar di Mall-Mall.

Diakses pada 5 Juli 2020, 8:18 pm WIB dari

https://www.nahimunkar.org/penampa

kan-kaos-bertuliskan-doa-kristianiberedar-mall-mall/

Nasution, H. (1974). Islam Ditinjau dari berbagai Aspeknya. Penerbit Bulan Bintang.

Novianti, N. (2007). Dampak Drama, Anime, dan Musik Jepang terhadap Minat Belajar Bahasa Jepang. Lingua Cultura, 1(2), 151-156. https://doi.org/10.21512/lc.v1i2.321
Qatar University website. (2019). Arabic for Non-Native Speakers. Diakses pada 5 Juli 2020, 8:14 pm WIB dari http://www.qu.edu.qa/artssciences/dep artments/anns

Rajagopalan, K. (2016). Language and identity: national, ethnic, religious (Book Review). WORD, 62(4), 276280.

https://doi.org/10.1080/00437956.201 $\underline{6.1248656}$

Rudy, M. (2016, 14 Juli). 7 Alasan Logis Kenapa Anda Musti Belajar Bahasa Arab. Diakses pada 5 Juli 2020, 8:26 pm WIB dari https://www.kiblat.net/2016/07/14/7alasan-logis-kenapa-anda-mustibelajar-bahasa-arab/

Suleiman, Y. (2003). The Arabic Language and National Identity: A Study in Ideology. In Edinburgh University Press.

https://doi.org/10.1525/jlin.2005.15.2. $\underline{281}$

Sutami, H. (2016). Fungsi dan Kedudukan Bahasa Mandarin di Indonesia. Paradigma, Jurnal Kajian Budaya, 2(2), 212-238. https://doi.org/10.17510/paradigma.v2 $\underline{\mathrm{i} 2.28}$

Tuasikal, M.A. (2016, 12 Januari). 7 Alasan Harus Belajar Bahasa Arab. Diakses pada 5 Juli 2020, 8:23 pm WIB dari

https://rumaysho.com/12720-7-alasanharus-belajar-bahasa-arab.html

UNIDA Gontor Website. (2019, 23 Agustus). Dosen PBA UNIDA Gontor 
Ikuti Program Pelatihan Bahasa Arab di Universitas Qatar. Diakses pada 5 Juli 2020, 8:15 pm WIB dari http://pba.unida.gontor.ac.id/dosenpba-unida-gontor-ikuti-programarabic-for-non-native-speaker-diuniversitas-qatar/

Wahab, M. A. (2007). Tantangan dan Prospek Pendidikan Bahasa Arab di Indonesia. Afaq Arabiyyah, 2(1), 118.

Wahyuni, I. (2017). Bahasa Arab Dalam Konteks Simbol Agama (Analisis Terhadap Tujuan Pembelajaran pada Perguruan Tinggi Islam). Zawiyah: Jurnal Pemikiran Islam, 3(2), 78-92.

Wahyuni, I. W., Ahmad, M., \& Mulyanti, S. (2011). Sikap Siswa Non Muslim dalam Mengikuti Pelajaran Arab Melayu. Jurnal Al-Hikmah, 8(1), 8895.

Widjaja, I. (2008). Kaligrafi yang Menyesatkan, Waspadalah! Retrieved March 17, 2020, from Indrawibowo.com website: https://perma.cc/98JV-EASY

Yahya, Y. K. (2018). Lexemes Mean God in Al-Qur'an and Arabic Gospel: Semantic Analysis. Lisanudhad, 05(02), 105-126.

Yahya, Y. K. (2019). Pengaruh Penyebaran Islam di Timur Tengah dan Afrika Utara: Studi Geobudaya dan Geopolitik. Al-Tsaqafa: Jurnal Peradaban Islam, 16(1), 44-62. 